\title{
Bioequivalence Study of 10 mg Olanzapine Tablets in Healthy Thai Volunteers
}

Somruedee Chatsiricharoenkul ${ }^{1 *}$, Suvimol Niyomnaitham ${ }^{1}$, Piyapat Pongnarin ${ }^{1}$, Korbtham Sathirakul ${ }^{2}$ and Supornchai Kongpatanakul ${ }^{1}$

${ }^{1}$ Department of Pharmacology, Faculty of Medicine Siriraj Hospital, Mahidol University, Thailand

${ }^{2}$ Department of Pharmacy, Faculty of Pharmacy, Mahidol University, Bangkok, Thailand

\begin{abstract}
Objective: The purpose of this study was to compare the bioequivalence of $10 \mathrm{mg}$ tablets of olanzapine between a generic drug (Olapin ${ }^{\circledR}-10$; Unison Laboratories Co., Ltd., Thailand) and a reference drug (Zyprexa ${ }^{\circledR}, \mathrm{Eli}^{\mathrm{B}}$ Lilly, England) in healthy volunteers.

Subjects and methods: A single dose, randomized, 2-period, 2-sequence, crossover study was conducted in 24 healthy Thai male and female volunteers. Each volunteer received a $10 \mathrm{mg}$ tablet of the reference or test drug under fasting condition with a washout period of at least 21 days. Blood samples were obtained at pre-dose and at various time points up to 120 hours after dosing. Olanzapine plasma concentrations were quantified by a validated method employing liquid chromatography with tandem mass spectrometry (LC-MS/MS).

Results: 24 volunteers completed both treatment periods. The geometric mean ratios (GMR) (test/reference) between the two formulations of olanzapine were $95.76 \%(90 \% \mathrm{Cl}, 88.55-103.55 \%)$ for $\mathrm{C}_{\max } ; 103.77 \%(97.49$ $110.46 \%)$ for $\mathrm{AUC}_{0-120}$; and $104.39 \%$ (98.20-110.98\%) for $\mathrm{AUC}_{0-\infty(\mathrm{obs})}$. There was no statistical difference of the Tmax between the two formulations $(p>0.05)$. One hundred and eight adverse events were reported from both formulations. Most of the adverse events were judged to be mild in intensity and did not require additional medical treatment.

Conclusion: No significant difference in the analysed pharmacokinetic parameters was found between the two formulations of $10 \mathrm{mg}$ olanzapine in the healthy Thai volunteers. The $90 \% \mathrm{Cl}$ of GMR of the pharmacokinetic parameters was entirely within the equivalence criteria (80-125\%). Therefore, it can be concluded that this two olanzapine tablet formulations were considered bioequivalent.
\end{abstract}

Keywords: Olanzapine; Bioequivalence; HPLC-MS/MS; Pharmacokinetic; Antipsychotic agent

\section{Introduction}

Olanzapine, a thienobenzodiazepine derivative, is an atypical antipsychotic agent with broad efficacy, eliciting a response in both the positive and negative symptoms of schizophrenia and bipolar I disorder. Olanzapine is approved in the US and Europe for the oral treatment of schizophrenia and bipolar I disorder within the dose range of 5-20 mg/day [1-3].

The pharmacokinetics of olanzapine are linear and doseproportional within the approved dosage range from $1 \mathrm{mg}$ up to 20 mg. Olanzapine is well absorbed following oral administration in both fed and fasted states. Food does not affect the rate or the extent of olanzapine absorption. Time of peak concentration ranges from 2-7 $\mathrm{h}[4,5]$. Olanzapine is extensively distributed throughout the body, binding primarily to albumin (90\%) and $\alpha_{1}$-acid glycoprotein (77\%). Olanzapine is eliminated extensively $(40 \%)$ of the dose by first pass metabolism. Direct glucuronidation and CYP1A2 mediated oxidation are the primary metabolic pathways for olanzapine. Phenotypic difference for CYP1A2 between races has been reported. The pharmacokinetics of olanzapine are similar amongst Japanese, Chinese and Caucasians [6,7]. The most common adverse effects of olanzapine in patients receiving olanzapine in short term were weight gain, somnolence, postural hypotension, dizziness, constipation, dyspepsia, dry mouth, increased appetite, tremor, personality disorder, asthenia and akathisia $[6,8]$.

This study was designed to assess the bioequivalence between a generic and a reference olanzapine in tablet formulation in terms of the extent and the rate of absorption.

\section{Methods}

\section{Study drugs}

Olapin ${ }^{\circledR}$ provided by Unison Laboratories Co., Ltd. (Thailand) (Lot No. T09/8-005, Mfg. date 3 January 2008, Exp. Date 3 January 2010) and Zyprexa ${ }^{\circledR}$ manufactured by Eli Lilly and Company limited, England (Lot No. A205276, Mfg. date 19 March 2008, Exp. Date 18 March 2009) were used as a test and a reference formulations, respectively. Both formulations were prepared as tablets containing $10 \mathrm{mg}$ olanzapine.

\section{Subjects}

Sample size was calculated using a power analysis $(\beta=0.2)$. It was determined that the power of the analysis of variance (ANOVA) was $>0.8$. Assuming the $\% \mathrm{CV}$ for $\mathrm{C}_{\max }$ and AUC was $20 \%$ [4,5], the $90 \% \mathrm{CI}$ indicated that a total of 20 subjects would be sufficient for the study. Additional 4 subjects were added to the calculated subject number to compensate for a possible predicted dropout rate of $20 \%$. All 24 healthy Thai volunteers (both male and female) aged between 18-45 years with

*Corresponding author: Somruedee Chatsiricharoenkul, MD, Department of Pharmacology, Faculty of Medicine Siriraj Hospital, Mahidol University, Bangkok 10700, Thailand, Tel: +66 2419 7565; Fax: +66 2411 5026; E-mail: sisci@ mahidol.ac.th

Received April 04, 2011; Accepted June 28, 2011; Published June 30, 2011

Citation: Chatsiricharoenkul S, Niyomnaitham S, Pongnarin P, Sathirakul K, Kongpatanakul S (2011) Bioequivalence Study of $10 \mathrm{mg}$ Olanzapine Tablets in Healthy Thai Volunteers. J Bioequiv Availab 3: 082-085. doi:10.4172/jbb.1000064

Copyright: (c) 2011 Chatsiricharoenkul S, et al. This is an open-access article distributed under the terms of the Creative Commons Attribution License, which permits unrestricted use, distribution, and reproduction in any medium, provided the original author and source are credited. 
a body mass index between $18-24 \mathrm{~kg} / \mathrm{m}^{2}$, were assessed to be in good physical condition by medical / laboratory examination, and eligible for study participation. They were well informed and provided written informed consent before participation. Clinical screening included a medical history, physical examination and the following laboratory tests: complete blood count, blood urea nitrogen, serum creatinine, aspartate aminotransferase, alanine aminotransferase, total bilirubin, alkaline phosphatase, fasting blood sugar, urinalysis and hepatitis B surface antigen. Eligible subjects did not smoke for at least 30 days before study participation. Exclusion criteria included allergic to either olanzapine or related drugs e.g. clozapine or its constituents. Pregnant woman or lactating woman or positive pregnancy test woman was ineligible for enrollment. Volunteers who used either any drugs affecting hepatic microsomal enzymes or other interaction drugs within 14 days before study participation, or had participated in other clinical studies within last 30 days also were excluded.

\section{Study design}

An open label, single dose, randomized, two-treatment, twoperiod, two-sequence crossover design with at least 21 days washout period was used in this study. The volunteers were randomly divided into two groups by the sequence of product taken (Test-Reference (TR) and Reference-Test (RT) group). Each subject was randomized to get either the test or reference product as a first drug by a preprinted randomization table that was created by using a randomization function in Microsoft Excel.

However, to avoid bias in analysis, the randomization code was blinded to bioanalytical staffs until the analysis for the last sample was finished. In each period, eligible subjects were confined to the research ward for $24 \mathrm{~h}$ after dosing. A single dose of $10 \mathrm{mg}$ olanzapine tablet either of the reference or test formulation was administered with $220 \mathrm{ml}$ water after at least $10 \mathrm{~h}$. fasting. A standardized meal was served at $4 \mathrm{~h}$ after the dosing and then every $4 \mathrm{~h}$ for two subsequent meals. The clinical part was conducted at Siriraj Clinical Research Center and the bioanalytical part was done at Siriraj Bioequivalence Center, Department of Pharmacology, Faculty of Medicine Siriraj Hospital, Mahidol University. The study protocol was approved by the Thailand Food and Drug Administration (FDA) and the Institutional Review Board of the Faculty of Medicine Siriraj Hospital. The study was performed in accordance with the Declaration of Helsinki for biomedical research involving human subjects and the Guideline for Good Clinical Practice.

\section{Sample collection}

In each period, a total of 16 blood samples were collected in lithium heparinized tube for determination of olanzapine plasma concentration. At each time point, $9 \mathrm{~mL}$ of blood sample was drawn via retained indwelling catheter (when possible) or direct venipuncture. Sampling time points were $0 \mathrm{~h}$ (pre-dose sample) and at $1,2,2.5,3$, $4,4.5,5,6,8,10,12,24,48,96$ and $120 \mathrm{~h}$ after the dosing. These 16 sampling time points were enough to provide an adequate estimation of $\mathrm{C}_{\max }$, AUC and terminal half-life. Blood samples were cooled on ice and centrifuged at $1942 \mathrm{x} \mathrm{g}$ for 10 minutes at approximately $4^{\circ} \mathrm{C}$. The plasma were collected and then kept at $-70^{\circ} \mathrm{C}$ until analysis.

\section{Determination of plasma olanzapine analysis}

Analysis of olanzapine was performed using a validated high performance liquid chromatography-tandem mass spectrometry (HPLC-MS/MS). Sample preparation was performed by liquidliquid extraction technique. Briefly, loratadine (Internal Standard;
IS) solution (200 $\mathrm{ng} / \mathrm{mL})$ was added to plasma sample or olanzapine spiked plasma and mixed for 10 seconds. All samples were mixed with $n$-Hexane: Isoamyl alcohol, and centrifuged at $12418 \times g$ or 15,000 rpm for $10 \mathrm{~min}$. Chromatographic separation was carried out on a HPLC-MS/MS with C18 column $(2.5 \mu \mathrm{m}, 50 \mathrm{~mm} \times 3.0 \mathrm{~mm}$ i.d. $)$. An isocratic mobile phase of acetonitrile and $10 \mathrm{mM}$ ammonium acetate $(60: 40, \mathrm{v} / \mathrm{v})$ was delivered with a flow rate of $0.2 \mu \mathrm{L} / \mathrm{min}$. Mass spectra were obtained using a Quattro Micro mass spectrometer (Micromass. UK) equipped with electrospray ionisation (ESI) source. The mass spectrometer was operated in the multiple reaction monitoring (MRM) mode. Electrospray ionization was in the positive ion mode. The mass transition ion-pair for olanzapine was obtained at $\mathrm{m} / z 313.20>256.27$ for primary daughter ion and $313.20>83.78$ for secondary daughter ion, whereas that of loratadine was at $m / z$ 383.07>337.18. The method was validated for specificity/selectivity, linearity,precision, accuracy, recovery of extraction and stability according to the US FDA guidelines [9].The data were obtained and analyzed usimg Masslynx 4.0 software. A linearity calibration curve in the range of 0.005 to $50 \mathrm{ng} / \mathrm{mL}$ was established for olanzapine $\left(r^{2}=0.999769\right)$. Precision, accuracy and stability were within the acceptable range.

\section{Pharmacokinetic and statistical analysis}

Pharmacokinetic parameters of olanzapine were obtained using non-compartmental analysis with WinNonlin ${ }^{\circledR}$ software version 3.1 (Scientific Consulting Inc., Apex, North Carolina).To compare the olanzapine bioequivalence between the test and reference formulations, the $\mathrm{AUC}_{0-120}$ (AUC from time 0 to $120 \mathrm{~h}$ after dosing), $\mathrm{AUC}_{0-\infty}$ (AUC from time to infinity) and $\mathrm{C}_{\max }$ (the maximum observed plasma concentration) were considered primary variables. $\mathrm{C}_{\max }$ and $\mathrm{T}_{\max }$ (the time taken to achieve maximum concentration) of olanzapine were taken directly from the concentration-time data. The $\mathrm{AUC}_{0-120}$ was calculated using trapezoidal approach. The $\mathrm{AUC}_{0-\infty}$ was calculated by the formulation $\mathrm{AUC}_{0-\infty}=\mathrm{AUC}_{0-\mathrm{t} \text { last }}+\left(\mathrm{C}_{\mathrm{t} \text { last }} / \lambda_{\mathrm{z}}\right)$, where $\mathrm{C}_{\mathrm{t} \text { last }}$ was the last detectable concentration. The $\lambda_{z}$ was the elimination rate constant calculated from the $\log (\ln )$ transformation of concentration-time curves. The plasma concentration half-life $\left(\mathrm{t}_{1 / 2}\right)$ was calculated by using the formulation $\mathrm{t}_{1 / 2}=0.693 / \lambda_{z}$.

Two-way analysis of variance (ANOVA) was applied to logtransformed data and for the effect of formulations, periods, sequences and subjects analyzed over $\mathrm{C}_{\max }, \mathrm{AUC}_{0-120}$ and $\mathrm{AUC}_{0-\infty}$. The difference between two related parameters was considered statistically significant when $p$-value equal to or less than 0.05 . A non-parametric statistical analysis was used to assess $\mathrm{T}_{\max }$ between test and reference formulations at $p=0.05$.

The deviation of sampling time point up to 5 minutes for samples within the first hour of dosing was acceptable. Subsequent samples were acceptable if a deviation was less than $5 \%$ of the scheduled time. However, the deviated data will not be included in mean at that sampling time point.

Bioequivalence between the two formulations was accepted when the $90 \%$ geometric confidence intervals of the ratio (test/reference) of least-squares means from the ANOVA of the log-transformed $\mathrm{C}_{\max }$ AUC $_{0-120}$ and $\mathrm{AUC}_{0-\infty}$ were within 80.00-125.00\%. [9,10].

\section{Tolerability assessment}

With safety concern for the volunteer [11], heart rate and blood pressure of each subject were closely monitored during the treatment period. Physical examination and vital signs measurement were performed prior to each period of drug administration as baseline 
Geometric Mean of Plasma Concentration Time Profiles

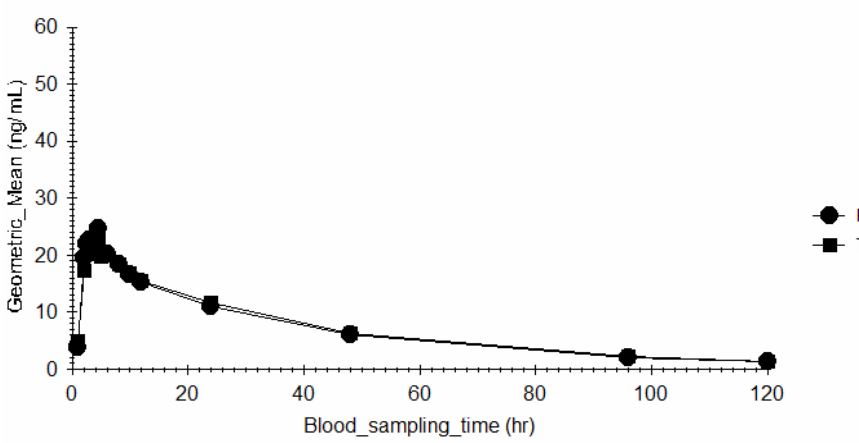

Figure 1: Geometric mean of plasma concentration-time profile of olanzapine after administration of $\operatorname{Olapin}^{\circledast}(T)$ and Zyprexa ${ }^{\circledast}(R)$ in 24 healthy volunteers.

\begin{tabular}{|l|l|l|l|l|}
\hline \multirow{2}{*}{ Parameter } & \multicolumn{2}{|l|}{ Olanzapine } & \multicolumn{2}{l|}{$\%$} \\
\cline { 2 - 5 } & Test & Reference & $\begin{array}{l}\text { ratio, Test/Reference } \\
(90 \% \mathrm{Cl})\end{array}$ & Power \\
\hline $\mathrm{C}_{\max }(\mathrm{ng} / \mathrm{mL})$ & $27.6(8.45)$ & $26.4(8.45)$ & $95.76(88.55-103.55)$ & 0.9978 \\
\hline $\mathrm{AUC}_{0-120 \mathrm{~h}}(\mathrm{ng} \cdot \mathrm{h} / \mathrm{mL})$ & $835(355)$ & $805(313)$ & $103.77(97.49-110.46)$ & 0.9999 \\
\hline $\mathrm{AUC}_{0-\infty}(\mathrm{ng} . \mathrm{h} / \mathrm{mL})$ & $901(408)$ & $863(366)$ & $104.39(98.20-110.98)$ & 0.9999 \\
\hline $\mathrm{T}_{\max }(\mathrm{h})$ & $3.53(1.00-$ & $3.00(1.00-$ & & \\
\hline $\mathrm{T}_{1 / 2}(\mathrm{~h})$ & $6.00)$ & $4.50)$ & & \\
\hline$\lambda_{z}(\mathrm{~h}-1)$ & $31.6(5.18)$ & $30.4(5.32)$ & & \\
\hline
\end{tabular}

AUC = area under plasma concentration-time curve, $C_{m a x}=$ maximal plasma concentration, $T_{\max }=$ time for the maximal plasma concentration, $T_{1 / 2}=$ half-life $\lambda_{z}=$ elimination rate constant. Data shown as geometric mean (SD) and median (range) for $T_{\max }$

Table 1: Pharmacokinetic parameters of olanzapine and bioequivalent analysis for the test $\left(\right.$ Olapin $\left.^{\circledR}\right)$ and reference $\left(\right.$ Zyprexa $\left.{ }^{\circledR}\right)$ formulations.

\begin{tabular}{|c|c|c|c|c|c|c|}
\hline Dependent & Effect & df & SS & MS & $\mathrm{F}$ & Probability \\
\hline $\operatorname{Ln}\left(C_{\max }\right)$ & Sequence & 1 & 0.3339 & 0.3339 & 2.64 & 0.1187 \\
\hline $\operatorname{Ln}\left(C_{\max }\right)$ & Subject_(Seq.) & 22 & 2. 7868 & 0.1267 & 5.09 & 0.0002 \\
\hline $\operatorname{Ln}\left(C_{\max }\right)$ & Treatment & 1 & 0.0226 & 0.0226 & 0.91 & 0.3513 \\
\hline $\operatorname{Ln}\left(C_{\max }\right)$ & Period & 1 & 0.0347 & 0.0347 & 1.39 & 0.2503 \\
\hline $\operatorname{Ln}\left(C_{\max }\right)$ & Error & 22 & 0.5474 & 0.0249 & & \\
\hline $\operatorname{Ln}\left(A \cup C_{0-120}\right)$ & Sequence & 1 & 0.5136 & 0.5136 & 2.52 & 0.1266 \\
\hline $\operatorname{Ln}\left(A \cup C_{0-120}\right)$ & Subject_(Seq.) & 22 & 4.4808 & 0.2037 & 12.85 & 0.0000 \\
\hline $\operatorname{Ln}\left(A \cup C_{0-120}\right)$ & Treatment & 1 & 0.0165 & 0.0165 & 1.04 & 0.3194 \\
\hline $\operatorname{Ln}\left(A \cup C_{0-120}\right)$ & Period & 1 & 0.0310 & 0.0310 & 1.96 & 0.1757 \\
\hline $\operatorname{Ln}\left(\mathrm{AUC}_{0-120}\right)$ & Error & 22 & 0.3488 & 0.0159 & & \\
\hline $\operatorname{Ln}\left(A \cup C_{0-\infty(o b s)}\right)$ & Sequence & 1 & 0.5511 & 0.5511 & 2.47 & 0.1304 \\
\hline $\operatorname{Ln}\left(A \cup C_{0-\infty(\text { obs })}\right)$ & Subject_(Seq.) & 22 & 4.9096 & 0.2232 & 14.66 & 0.0000 \\
\hline $\operatorname{Ln}\left(A \cup C_{0-\infty(o b s)}\right)$ & Treatment & 1 & 0.0222 & 0.0222 & 1.46 & 0.2404 \\
\hline $\operatorname{Ln}\left(A \cup C_{0-\infty(o b s)}\right)$ & Period & 1 & 0.0292 & 0.0292 & 1.92 & 0.180 I \\
\hline $\operatorname{Ln}\left(A \cup C_{0-\infty(o b s)}\right)$ & Error & 22 & 0.3349 & 0.0152 & & \\
\hline
\end{tabular}

Table 2: ANOVA table for period, sequence and treatment effects for the logtransformed data of $C_{\max }, A \cup C_{0-120}$ and $A \cup C_{0-\infty(o b s)}$

and were repeated at $24,36,48,96$, and $120 \mathrm{~h}$. The observation for any adverse drug effects was carefully monitored throughout the study.

\section{Results}

\section{Volunteer profile}

24 healthy Thai adults were enrolled and randomly divided into 2 groups (test-reference (TR) and reference-test (RT)). Each group consisted of twelve subjects. Their demographic characteristics were similar in both groups. There were 8 males and 4 females in TR and 4 males and 8 females in RT. Mean \pm SD of age, weight, height, and BMI were $25.8 \pm 4.7$ years, $61.6 \pm 6.5 \mathrm{~kg}, 167.0 \pm 6.5 \mathrm{~cm}$, and $22.0 \pm 2.1 \mathrm{~kg} /$ $\mathrm{m}^{2}$ for TR, and $27.7 \pm 4.3$ years, $57.9 \pm 11.2 \mathrm{~kg}, 164.6 \pm 10.1 \mathrm{~cm}$, and 21.1 $\pm 2.0 \mathrm{~kg} / \mathrm{m}^{2}$ for RT, respectively.

\section{Bioavailability and pharmacokinetic equivalence}

Olanzapine pharmacokinetics: The geometric mean plasma concentration-time profile of olanzapine after oral administration from 24 healthy volunteers was illustrated (Figure 1). The pharmacokinetic parameters for olanzapine and bioequivalence analysis were summarized (Table 1). The ANOVA analysis of sequence, subject nested within sequence, period and formulation as factors were demonstrated (Table 2).

Bioequivalence analysis: The statistical analysis obtained from this study showed that the $90 \%$ confidence interval of the geometric mean ratio (test/reference) of $\mathrm{C}_{\max }(95.76 \%$ (88.55\%-103.55\%)), $\mathrm{AUC}_{0-120}(103.77 \%(97.49 \%-110.46 \%))$ and $\mathrm{AUC}_{0-\infty}(104.39 \%(98.20 \%$ - $110.98 \%)$ ) were entirely within the equivalence criteria $(80.00$ $125.00 \%)$. There was no statistical difference of median $\mathrm{T}_{\text {max }}$ between the test and reference formulations $(p>0.05)$.

\section{Tolerability}

All subjects were able to tolerate the two olanzapine formulations. A total of 108 adverse events were reported over the two study periods. 58 of these events were related to the reference product whereas 50 events were related to the test product. As anticipated, all subjects experienced substantial drowsiness and dizziness in all study periods. The most common events were drowsiness, dizziness and dry mouth/ lip. All adverse events were mild in intensity and mostly related to the study drug. Most of them did not require additional medical treatment. No serious adverse effect was observed throughout the study. All of adverse events were reported to the Institutional Review Board of Faculty of Medicine Siriraj Hospital, Mahidol University (Table 3).

\section{Discussion}

The olanzapine plasma concentration-time profiles of the generic and branded formulations were comparable. The pharmacokinetic parameters in these healthy Thai volunteers were in agreement with the previously report $[4,6,7]$.

\begin{tabular}{|l|l|l|l|}
\hline \multirow{2}{*}{ Adverse events } & \multicolumn{2}{l|}{ Reported incidence } & Total \\
\cline { 2 - 4 } & Test & Reference & \\
\hline Drowsiness & 24 & 24 & 48 \\
\hline Dizziness & 13 & 13 & 26 \\
\hline Dry mouth/lip & 6 & 7 & 13 \\
\hline Headache & 1 & 2 & 3 \\
\hline Fainting/Near syncope & 2 & 1 & 3 \\
\hline Common cold/URI & - & 2 & 2 \\
\hline Nausea & 1 & 1 & 2 \\
\hline Hypotension & 1 & 1 & 2 \\
\hline Diarrhea/Loose stool & - & 2 & 2 \\
\hline Mood disturbance & - & 2 & 2 \\
\hline Running nose & - & 1 & 1 \\
\hline Vertigo & - & 1 & 1 \\
\hline Increased appetite & - & 1 & 1 \\
\hline Hematoma on scalp & 1 & - & 1 \\
\hline Tremor & 1 & - & 1 \\
\hline
\end{tabular}

Table 3: Incidence of adverse events. 
Citation: Chatsiricharoenkul S, Niyomnaitham S, Pongnarin P, Sathirakul K, Kongpatanakul S (2011) Bioequivalence Study of 10 mg Olanzapine Tablets in Healthy Thai Volunteers. J Bioequiv Availab 3: 082-085. doi:10.4172/jbb.1000064

The ANOVA analysis demonstrated no significant effects from period, sequence and treatment to the log-transformed data of $\mathrm{C}_{\max }$, $\mathrm{AUC}_{0-120}$ and $\mathrm{AUC}_{0-\infty}$. However, the significance in subject nested in sequence was detected $(p<0.05)$ for all parameters that is usually seen in small sample size as observed in crossed over phase I and bioequivalence studies. The powers of the tests conducted on $\mathrm{C}_{\max }, \mathrm{AUC}_{0-120}$ and $\mathrm{AUC}_{0}$ analyzed with WinNonlin were 99.78, 99.99 and 99.99 respectively, indicating that a sample size of 24 volunteers was adequate. In a singledose administration of olanzapine $\left(\right.$ Zyprexa $\left.^{\circledR}\right)$, our study showed that the $\mathrm{C}_{\max }$ was reached within $3 \mathrm{~h}$. The plasma concentration of olanzapine was decreased with a terminal elimination half-life $\left(t_{1 / 2}\right)$ of approximately $30 \mathrm{~h}$. Overall, the obtained pharmacokinetic parameters were in agreement with others $[7,13]$.

Although atypical anti-psychotics, olanzapine, is generally better tolerated than conventional agents, it may still cause untoward reactions due to individual differences in drug absorption and metabolism [11]. In our study, one of the most common adverse events was dizziness that may lead to orthostatic hypotension or even near syncope especially during the initial dose titration. This side effect may be due to its $\alpha_{1}$-adrenergic antagonistic properties [11]. However, with close monitoring, our volunteers tolerated both olanzapine formulations.

The bioequivalence study of two formulations of olanzapine tablet between the test product and the reference product in 24 healthy male and female volunteers was completed. The $90 \%$ confidence interval of the logarithmic transformed of $\mathrm{C}_{\max }$ and $\mathrm{AUC}_{0-120}$ and $\mathrm{AUC}_{0-\infty}$ were contained in $80.00-125.00 \%$. Non-parametric Friedman's test for $\mathrm{T}_{\max }$ was also demonstrated no significantly different between both formulations $(p>0.05)$. In conclusion, the test formulation (Olapin $\left.{ }^{\circledR}-10\right)$ was bioequivalent to the reference formulation $\left(\right.$ Zyprexa $\left.^{\circledR}\right)$ in terms of rate and amount of absorption.

\section{Acknowledgements}

The authors would like to acknowledge Unison Laboratories Co., Ltd. for funding and providing both olanzapine formulations. The authors would like to thank Miss Patcharaporn Manopinives, Miss Manatchaya Wanawatanakun and Miss Siriluk Suddhichupaiboon for their kindly helping. Somruedee Chatsiricharoenkul (The author) is supported by "Chalermprakiat" grant, Faculty of Medicine Siriraj Hospital, Mahidol University.

\section{References}

1. Bhana N, Foster RH, Olney R and Plosker GL (2001) Olanzapine: An updated review of its use in the management of schizophrenia. Drugs 61:111-161.

2. Bhana N, Perry CM (2001) Olanzapine: A review of its use in the treatment of bipolar I disorder. CNS Drugs 11: 871-904

3. McCormack PL, Wiseman LR (2004) Olanzapine: A review of its use in the management of bipolar I disorder. Drugs 64: 2709-26.

4. Markowitz JS, DeVane L, Malcolm RJ, Gefroh HA, Wang JS, et al. (2006) Pharmacokinetics of olanzapine after single-dose oral administration of standard tablet versus normal and sublingual administration of an orally disintegrating tablet in normal volunteers. J Clin Pharmacol 46: 164-171.

5. Wang CY, Zhang ZJ, Li WB, Zhai YM, Cai ZJ, et al. (2006) The differentia effects of steady-state fluvoxamine on the pharmacokinetics of olanzapine and clozapine in healthy volunteers. J Clin Pharmacol 44: 785-792.

6. Callaghan JT, Bergstrom RF, Ptak LR, Beasley CM (1999) Olanzapine: pharmacokinetic and pharmacodynamic profile. Clin Pharmacokinet. 37: 177 193.

7. Sathirakul K, Chan C, Teng L, Bergstrom RF, Yeo KP, et al. (2003) Olanzapine pharmacokinetics are similar in Chinese and Caucasian subjects. $\mathrm{Br} \mathrm{J}$ Clin Pharmacol 56: 184-187.

8. Eli Lilly, Nederland. Evaluation of medicinal products: Medicinal Products. Zyprexa [online]. 2006. Available from www.emea.eu.int [Accessed: January 11, 2007].

9. U.S. Department of Health and Human Services Food and Drug Administration Center for Drug Evaluation and Research (CDER). Guidance for Industry: Bioavailability and bioequivalence studies for orally administered drug products-general considerations. March 2003 BP (revision 1).

10. European Agency for the Evaluation of Medicinal Products Evaluation of Medicines for Human Use. Note for guidance on the investigation of bioavailability and bioequivalence. 26 July 2001.

11. Markowitz JS, DeVane L, Boulton DW, Liston HL, Risch SC (2002) Hypotension and bradycardia in a healthy volunteer following a single $5 \mathrm{mg}$ dose of olanzapine. J Clin Pharmacol 42: 104-106.

12. Wang CY, Zhang ZJ, Li WB, Zhai YM, Cai ZJ, et al. (2004) The differentia effects of steady-state fluvoxamine on the pharmacokinetics of olanzapine and clozapine in healthy volunteers. J Clin Pharmacol 44: 785-792.

13. Cánovas M, Torres F, Domenech G, Cebrecos J, Pelagio P, et al. (2011) Bioequivalence evaluation of two dosage forms of olanzapine $10 \mathrm{mg}$ formulations in healthy volunteers. Arzneimittelforschung 61: 75-79. 